Department of Economics and Finance

\author{
University of Guelph
}

Discussion Paper 2018-04

\title{
Pipeline capacity and the dynamics of Alberta crude oil price spreads
}

\author{
By: \\ Gregory Galay \\ University of Guelph \\ ggalay@uoguelph.ca \\ Henry Thille \\ University of Guelph \\ hthille@uoguelph.ca
}




\title{
Pipeline capacity and the dynamics of Alberta crude oil price spreads*
}

\author{
Gregory Galay \\ Department of Economics \& Finance \\ University of Guelph \\ E-mail: ggalay@uoguelph.ca
}

\author{
Henry Thille \\ Department of Economics 8 Finance \\ University of Guelph \\ E-mail: hthille@uoguelph.ca
}

August 7, 2018

\begin{abstract}
From 2011 until the end of 2014, a larger than normal price spread emerged between West Texas Intermediate (WTI) and Western Canadian Select (WCS). This led many participants in Canada's energy sector to advocate for the expansion of Canada's crude oil pipeline system as they believed that excess supply could not be moved from production regions in Northern Alberta to those markets that would yield the highest return. This article considers the impact constrained transportation capacity has on the price spread between WCS and other world prices such as WTI. A Markov-switching model is used to identify regimes associated with binding/non-binding pipeline capacity. Our results confirm the predictions of models of spatial arbitrage under capacity constraints. When there is sufficient transportation capacity the price spreads reflect transport costs (includes fees, insurance, etc.) plus any premium for the quality difference between the crude oils compared. However, during periods of tight capacity the spread becomes more volatile and on average exceeds transport costs plus the quality premium. We compare our results to newly available pipeline data and find that periods of tight capacity as identified through the price data are substantially fewer than that suggested by the pipeline capacity data.
\end{abstract}

JEL Classification: Q41, L95

Keywords: Crude oil prices, spatial pricing, pipeline congestion, Markov-switching autoregression

${ }^{*}$ We thank Janelle Mann and conference participants at the 2017 Canadian Resource and Environmental Economics Study Group meeting and the 2018 Canadian Economics Association meeting for useful comments on an earlier draft of this paper. 


\section{Introduction}

It is well established that the price of a commodity critically depends on its quality and its location. Samuelson (1952) and Takayama and Judge (1971) show that spatial arbitrage ensures the price of a commodity in one location is equal to the price of the commodity in another location less transport costs (includes fees, insurance, etc.) between the two locations so that price differences equal transport costs. However, in a spatial arbitrage model with transportation capacity constraints, Coleman (2009) found that on rare occasions the price difference between two locations can exceed transport costs when transportation capacity is fully utilized. His results suggest the price difference process may be governed by at least two regimes. In one regime, the price difference fluctuates around transport costs as inventories and excess transportation capacity are sufficient to smooth fluctuations in supply and demand across regions. In the other regime, when capacity is fully utilized, the price difference exceeds transport costs as excess supply cannot be moved from one region to the other causing higher prices in the importing region and lower prices in the exporting region.

We examine the impact constrained transportation capacity may have on the distribution of price differentials faced by producers of heavy crude oil in Alberta, Canada. While we consider other price differentials, our main focus will be on the spread between West Texas Intermediate (WTI) and Western Canadian Select (WCS). WTI is a light, sweet crude oil located in Cushing, Oklahoma and it is the benchmark crude oil in North America. WCS is a heavy, sour crude oil located in Hardisty, Alberta and it is the benchmark for heavy crude oil in Canada. We plot the spread between WTI and WCS in Figure 1. Historically, the difference in price between the two crude oils as reflected transport costs and quality differences. From 2005 until 2010, the average monthly WTI-WCS spread was $\$ 13.13 .{ }^{1}$ The National Energy Board (2014) estimates the cost of transporting crude oil via pipeline from Hardisty to Cushing to be between $\$ 5$ to $\$ 6.55$ per barrel depending on the quality of the crude oil and the system that is used. We estimate the market value of the quality difference to be approximately $\$ 6.92 .^{2}$ Given these estimates, transport costs plus quality differences range from $\$ 11.92$ to $\$ 13.47$. However, from 2011 to 2014 , the WTI-WCS spread increased to an average of $\$ 20.61$. This elevated average exceeded transport costs and quality differences. Many observers of the Canadian energy sector are certain that the increase in the WTI-WCS spread, over this period, is the result of constrained transportation capacity as pipelines are generally full and more crude oil is being shipped by rail to avoid bottlenecks despite the higher costs. ${ }^{3}$ They believe expanding pipeline capacity is necessary for the continued development of the Alberta oil sands as more capacity will result in a reduction of the WTI-WCS spread. Recently, Galay (2018) has shown that a large sustained price spread reduces the value of operating oil extraction projects and projects in the planning stages.

\footnotetext{
${ }^{1}$ Prices are in U.S. dollars unless otherwise indicated.

${ }^{2}$ The estimate of the market value of the quality difference is simply the average weekly Brent-Mexican Maya spread over the period from May 2008 to February 2016. This data was collected from Bloomberg. Brent is a light, sweet crude oil similar in quality to WTI and Mexican Maya is a heavy, sour crude oil similar in quality to WCS. Both Brent and Mexican Maya have access to tidewater and therefore face much lower transport costs than landlocked WTI and WCS.

${ }^{3}$ According to McKeown et al. (2016), in 2013, crude oil transported by rail reached 200,000 bbl/d. Compared to the previous year, exports by rail increased by $177 \%$. The National Energy Board estimates that rail costs are roughly double or triple the cost of pipelines.
} 
Figure 1: WTI-WCS price spread

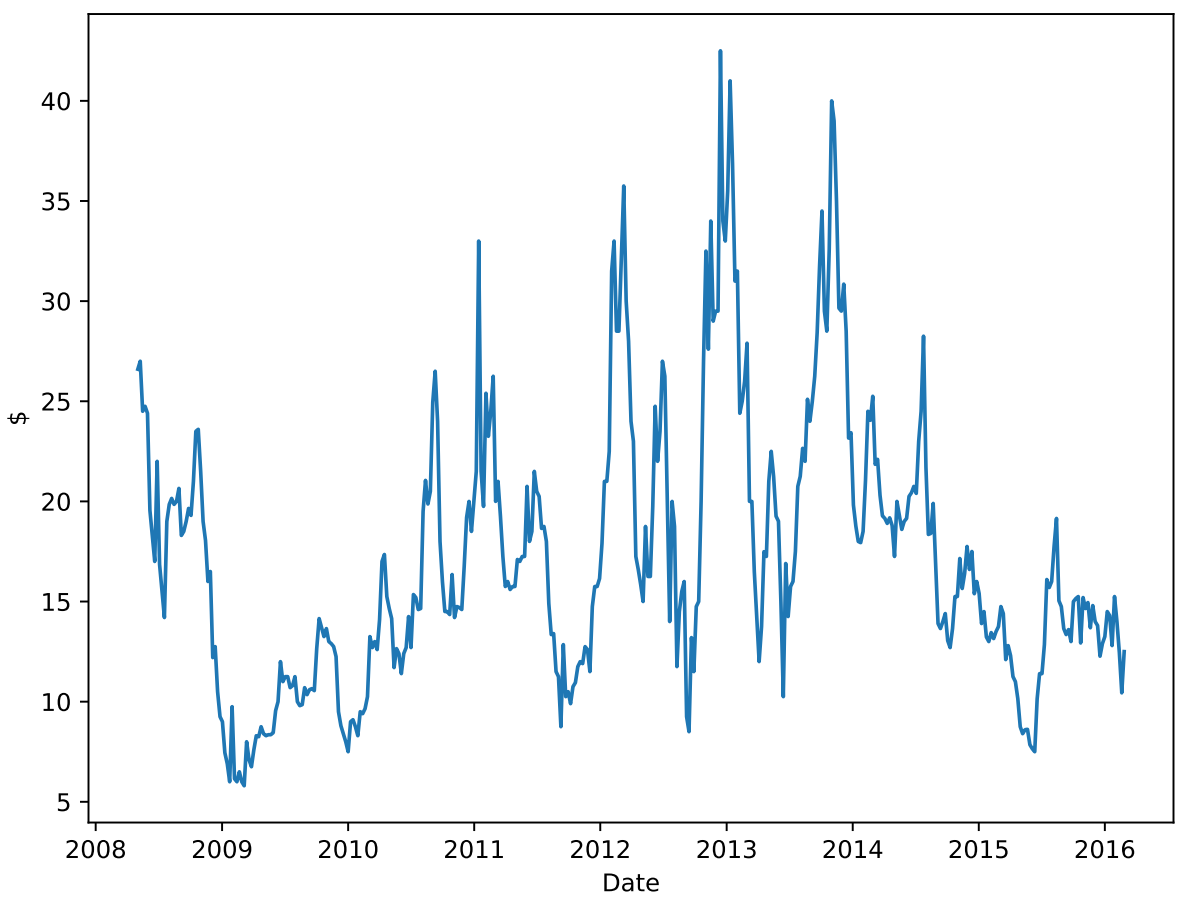

In this paper, we analyze price spreads as Markov-switching processes in which regimes correspond to episodes of binding/non-binding transportation capacity. In the spatial arbitrage literature, binding transportation capacity is the switch that causes the price difference to exceed the bounds suggested by the absence of arbitrage. Here, transportation capacity is treated as an unobserved state variable that evolves according to a Markov process. Markov-switching models are useful for series that are believed to transition over a finite set of unobserved regimes, allowing the process to evolve differently in each regime. Our estimated models are compared to the predictions in the literature. If one regime is characterized by a low mean spread and low variance and the other regimes are characterized by a high mean spread and high variance then we would argue that capacity constraints affect the distribution of the spread. ${ }^{4}$

The effects of pipeline capacity constraints on spatial prices has been examined in the case of natural gas pipelines. Oliver et al. (2014) examine the potential for pipeline capacity to affect price differentials for a natural gas pipeline network in the Rocky Mountain region of the western United States. They find evidence that pipeline congestion leads to higher transportation charges, increasing the price differential between nodes one the network. Avalos et al. (2016) estimate the shadow price of capacity for two natural gas pipelines in Florida and Southern California with a reduced-form model for the gas price levels. They find that tight capacity is associated with a substantial and statistically significant increase

\footnotetext{
${ }^{4}$ If alternative shipping modes, such as rail, may also be capacity constrained then there is the possibility of more than two regimes.
} 
in price.

A substantial literature exists that seeks to determine whether the world crude oil market is integrated or not, i.e., whether the market is global or regional in nature. Commonly this has been done by testing whether or not particular oil prices are cointegrated. Recently, a number of papers have provided evidence that the relationship between these world oil prices is nonlinear. Recent contributions include Kuck and Schweikert (2017), Mann and Sephton (2016), Reboredo (2011), Fattouh (2010), Hammoudeh et al. (2008), and Zhang and Zhang (2015). In this paper, we do not ask whether or not prices are cointegrated as we focus mainly on prices in a region clearly connected by pipeline, but rather ask whether the dynamics of prices are consistent with the predictions of the capacity constrained spatial pricing model.

Our results for both the WTI-WCS spread and the Mexican Maya-WCS spread are consistent with the theory. We find evidence of two regimes: one with a relatively low mean and variance, which we interpret as a non-binding capacity regime; and another with higher mean and variance, which we interpret as a binding capacity regime. The fact that we find similar results for the price spread with Mexican Maya as for WTI provides additional evidence that the regime changes are driven by pipeline congestion and not by changes in the quality premium. Our procedure also provides an estimate of the shadow price of additional pipeline capacity which is of interest for the valuation of new pipeline infrastructure investment. Finally, we compare our estimates of capacity constraints derived from price data to some recently released data on capacity utilization in Canadian pipelines.

The rest of the article is organized as follows. Section 2 provide a brief overview of the spatial pricing model under capacity constraints. Section 3 presents the Markov-switching model. Section 4 describes the data, sections 5 and 6 provide provide results for both fixed and time-varying transition probabilities in the Markov-switching model. Finally, Section 7 compares the results to data related to pipeline capacity tightness.

\section{The Spatial Pricing Model}

Our empirical model is derived from the theory of spatial price equilibrium in the presence of capacity constraints (Cremer and Laffont (2002), Cremer et al. (2003), Coleman (2009)). We first present a simple summary of the theory and then turn to the implications for our empirical model. Consider two locations that we denote upstream $(U)$ and downstream $(D) .{ }^{5}$ Let $P_{U}$ and $P_{D}$ be the prices at the two locations. The transport infrastructure between the two locations has a capacity, $K$, and the marginal shipping cost is denoted $T{ }^{6}$ Desired shipments are denoted $S^{*}(X)$, where $X$ is a vector of variables that influence the demand for shipping, such as $P_{U}, P_{D}$, and any shocks to demand or supply at either location.

Arbitrage opportunities exist if the downstream price exceeds the upstream price plus

\footnotetext{
${ }^{5}$ The usual treatment of spatial arbitrage allows for trade flows in both directions. However, in our application the flow is only one direction: from Alberta to a downstream location, so we present this simpler case.

${ }^{6} T$ also includes any quality differences between the products sold at $P_{U}$ and $P_{D}$. For example, WTI and WCS apply to crude oils with different characteristics and for simplicity we consider the quality differential as a component of $T$.
} 
any shipping costs and quality differentials: $P_{D}>P_{U}+T$. Absent a binding transport capacity arbitrageurs would buy in the upstream market, driving up $P_{U}$, ship and sell in the downstream market, driving down $P_{D}$ until $P_{D} \leq P_{U}+T .{ }^{7}$ However, this may not happen with a capacity constraint on shipments: if $S^{*}(X) \geq K$, arbitrage is unable to remove the $P_{D}>P_{U}+T$ situation. As a consequence, the equilibrium price differential $P_{D}-P_{U}$ must satisfy

$$
P_{D}-P_{U}= \begin{cases}T & \text { if } S^{*}(X)<K, \\ T+\lambda & \text { if } S^{*}(X) \geq K,\end{cases}
$$

where $\lambda=\max \left(0, P_{D}-P_{U}-T\right)$ is the shadow price of capacity. ${ }^{8}$ The prediction of the spatial arbitrage model with capacity constraints is that the price differential can be in one of two regimes, depending on whether the capacity constraint is binding or not.

Coleman (2009) presents a more general dynamic version of the above in which the effects of spatial arbitrage combined with inter-temporal arbitrage by allowing storage of the commodity at both locations. The effects of storage are know to result in autoregressive processes for prices (Samuelson (1971)). Given particular distributions for random shocks occurring in each market, Coleman demonstrates a number of predictions for the equilibrium distributions of the endogenous variables in the model. For our purposes, the relevant ones are that both the mean and variance of the price differential are higher the tighter the capacity constraint is. We see from (1) that the mean price will be higher if the constraint does bind at least occasionally. At the same time, binding capacity constraints imply a wider range of variation for the price differential, resulting in a larger variance. Consequently, the capacity constrained spatial price model suggests the following hypothesis:

Hypothesis: Price differentials follow a two regime autoregressive process with one regime characterized by a higher mean and higher variance than the other.

\section{Empirical Model}

A natural candidate for testing our hypothesis is the autoregressive Markov switching model. ${ }^{9}$ Let $y_{t}$ denote the price spread between two crude oil streams. The process for $y_{t}$ is

\footnotetext{
${ }^{7}$ As we assume that transport from downstream to upstream is not possible, we allow $P_{D}<P_{U}+T$ in which case shipments would be zero. As we do not observe zero shipments in our data, we do not concern ourselves with this case.

${ }^{8}$ Coleman (2009) allows for the transport cost to be endogenous in which case $\lambda$ represents the extent to which the price of transporting the commodity rises when capacity binds and becomes a rent earned by the owner of the transportation infrastructure.

${ }^{9}$ The Markov-switching model was initially developed by Goldfeld and Quandt (1973) for linear regression equations. Hamilton (1989) extended Goldfeld and Quandt's Markov-switching regression to allow for autoregressive processes and provided a nonlinear filter for estimation. Following Hamilton's seminal paper, Markov-switching models have become widely applied in economics. Hamilton modelled the growth rate of GDP as a switching process to capture the asymmetric behaviour observed over expansions and recessions. Garcia and Perron (1996) modelled real interest rates under three regimes, Engel and Hamilton (1990) model US exchange rates, and Kim et al. (1998) model monthly stock returns. More recently, Zhang and Zhang (2015) modelled Brent, WTI, and the Brent-WTI spread pre and post financial crisis use a three regime Markov switching model.
} 
then

$$
y_{t}-\mu_{s_{t}}=\rho_{s_{t}}\left(y_{t-1}-\mu_{s_{t-1}}\right)+\epsilon_{t},
$$

where $\mu_{s_{t}}$ is the regime specific mean spread, $\rho_{s_{t}}$ is the regime specific autoregressive coefficient, ${ }^{10} \epsilon_{t}$ is the independent and identically distributed error term with regime specific variance $\sigma_{s_{t}}^{2}$, and $s_{t}=1,2, \ldots, n$ denotes the regime. The state of the regime is not directly observable, if it was we could simply estimate equation (2) with the use of dummy variables. However, we do not know with certainty which regime prevails, therefore, the transition probabilities are defined as

$$
p\left(s_{t}=j \mid s_{t-1}=i\right)=p_{i, j}, \quad(i, j=1,2, \ldots, n)
$$

where $\sum_{j=1}^{n} p_{i, j}=1$, for $i=1,2, \ldots, n$.

If we assume there are only two regimes $(n=2)$ governing the price spread process then we let regime $1, s_{t}=1$, represent periods when there is sufficient transportation capacity in place and regime $2, s_{t}=2$, represent periods when there is insufficient transportation capacity. If we allow for three regimes $(n=3)$ : regime 1 will continue to represent periods when there is sufficient transportation capacity, regime 2 will represent periods when pipeline capacity is constrained but alternative shipping modes are available, and regime 3 will represent periods when all modes of transportation are fully utilized.

The conditional density of an observed value of $y_{t}$ is:

$$
f\left(y_{t} \mid s_{t}, s_{t-1}, \psi_{t-1}\right)=\frac{1}{\sqrt{2 \pi \sigma_{s t}^{2}}} \exp \left\{\frac{-\left(y_{t}-\mu_{s_{t}}-\rho_{s_{t}}\left(y_{t-1}-\mu_{s_{t-1}}\right)\right)^{2}}{2 \sigma_{s_{t}}^{2}}\right\}
$$

where $\psi_{t-1}$ is all information available up to time $t-1$. The conditional likelihood value for each observation $y_{t}$ can be written as a weighted average of the conditional densities in (4) as follows:

$$
\begin{aligned}
L_{t}(\theta)=f\left(y_{t} \mid \psi_{t-1}\right) & =\sum_{s_{t}=1}^{n} \sum_{s_{t-1}=1}^{n} f\left(y_{t}, s_{t}, s_{t-1} \mid \psi_{t-1}\right) \\
& =\sum_{s_{t}=1}^{n} \sum_{s_{t-1}=1}^{n} f\left(y_{t} \mid s_{t}, s_{t-1}, \psi_{t-1}\right) p\left(s_{t}, s_{t-1} \mid \psi_{t-1}\right)
\end{aligned}
$$

where the weights are the joint probability of regime $s_{t}$ and $s_{t-1}$ occurring given all past information up to $t-1$

$$
p\left(s_{t}, s_{t-1} \mid \psi_{t-1}\right)=p\left(s_{t} \mid s_{t-1}\right) p\left(s_{t-1} \mid \psi_{t-1}\right)
$$

with the probability of regime $s_{t-1}$ conditional on all information up to $t-1$

$$
p\left(s_{t-1} \mid \psi_{t-1}\right)=\sum_{s_{t-2}} p\left(s_{t-1}, s_{t-2} \mid \psi_{t-1}\right)
$$

\footnotetext{
${ }^{10}$ Higher order autoregressive processes were examined and rejected in favour of the first order model.
} 
and the joint probability of regime $s_{t-1}$ and $s_{t-2}$ given all available information at time $t-1$

$$
p\left(s_{t-1}, s_{t-2} \mid \psi_{t-1}\right)=\frac{f\left(y_{t-1}, s_{t-1}, s_{t-2} \mid \psi_{t-2}\right)}{f\left(y_{t-1} \mid \psi_{t-2}\right)} .
$$

The log-likelihood function is then

$$
\begin{aligned}
\mathcal{L}(\theta) & =\sum_{t=1}^{T} \ln L_{t}(\theta) \\
& =\sum_{t=1}^{T} \ln \left\{\sum_{s_{t}=1}^{n} \sum_{s_{t-1}=1}^{n} f\left(y_{t} \mid s_{t}, s_{t-1}, \psi_{t-1}\right) p\left(s_{t}, s_{t-1} \mid \psi_{t-1}\right)\right\}
\end{aligned}
$$

where $\theta=\left(\mu_{1}, \ldots, \mu_{n}, \rho_{1}, \ldots, \rho_{n}, \sigma_{1}^{2}, \ldots, \sigma_{n}^{2}\right)$ is a vector of parameters. The model parameters and probabilities are computed using the nonlinear filtering algorithm for maximum likelihood as described in Hamilton (1994) and Kim and Nelson (1999). ${ }^{11}$

\section{Data}

Weekly crude oil spot price data covering a period of 9 years from May 2, 2008 to February 26, 2016 was obtained from Bloomberg for this study. The price data includes information on five crude oil price streams: Brent, Edmonton Syncrude Sweet (ESS), Mexican Maya, WCS, and WTI. Spot prices are measured in US dollars per barrel. Table 1 presents the descriptive statistics for the price data. Brent, ESS, and WTI are light, sweet crude oils while Mexican Maya and WCS are heavy, sour crude oils. ${ }^{12}$ ESS, WCS, and WTI are land-locked crude oils meaning they do not have easy access to ports for shipping. ESS and WCS are located in Edmonton and Hardisty, Alberta, respectively and WTI is located in Cushing, Oklahoma. Brent and Mexican Maya are tidewater crude oils. Brent is located in the North Sea and Mexican Maya is located in the Gulf Coast. Over the sample period, light, sweet crude oils (Brent, ESS, and WTI) have higher average prices than heavy, sour crude oils (WCS and Mexican Maya) and tidewater crude oils (Brent and Mexican Maya) have higher average prices than land-locked crude oils (ESS, WCS, and WTI).

The National Energy Board (NEB) requires oil pipeline companies to report monthly data on the volume (in cubic metres of oil flowed per day) at key points on the system by product, total monthly nominations in cubic metres per day, and apportionment percent. ${ }^{13}$ We collected this data for the period from May 2008 to February 2016 from the NEB for three Group 1 pipeline companies: Enbridge Mainline, TransCanada Keystone, and Trans Mountain. Monthly data for crude-by-rail shipments and inventories held by crude oil transporters was collected from Statistics Canada Tables 404-0002 and 126-0001. Table 2 presents

\footnotetext{
${ }^{11}$ The python library statsmodels is used to estimate the parameters of the two regime Markov-switching model.

${ }^{12}$ Light, sweet crude oils are higher quality crude oils than heavy, sour crude oils because they are easier to refine and the resulting output is more valuable. As a result, they will typically receive a higher price in the market.

${ }^{13}$ Apportionment percent is the percent by which each shipper's nominated volume is reduced if total nominations by all shippers if greater than the volume the pipeline can transport.
} 
Table 1: Descriptive Statistics: Crude Oil Prices (Weekly)

\begin{tabular}{lrrrrr}
\hline \hline & WTI & WCS & ESS & Maya & Brent \\
Mean & 81.91 & 64.69 & 82.50 & 78.26 & 88.79 \\
St. Dev. & 23.27 & 20.64 & 24.49 & 24.75 & 26.91 \\
Min. & 29.42 & 15.12 & 28.17 & 21.68 & 27.93 \\
Max. & 145.29 & 129.63 & 148.09 & 129.77 & 144.38 \\
Skew. & -0.32 & -0.20 & -0.16 & -0.49 & -0.42 \\
Kurt. & -0.32 & 0.07 & -0.44 & -0.87 & -1.02 \\
\hline \multicolumn{5}{c}{ Number of Observations $=409$} \\
\hline \hline
\end{tabular}

the descriptive statistics for the transportation and storage data. The pipeline data has been aggregated over key points and products. Canadian Mainline is the largest pipeline transporting light crude, heavy crude, and refined petroleum products from Alberta to Eastern Canada, the Midwest U.S., and the Gulf Coast. Keystone is the second largest pipeline transporting, primarily heavy crude, from Alberta to the Midwest U.S. and the Gulf Coast. Keystone began transporting crude oil in July 2010. Trans Mountain is the smallest pipeline included in the study, it ships light crude, heavy crude, and refined petroleum products from Alberta to British Columbia. Crude-by-rail shipments and inventories held by transporters are measured in thousands of cubic metres. ${ }^{14}$ Crude-by-rail transport roughly half the crude oil transported by the Trans Mountain pipeline system (divide average by 30).

\section{Results}

Heavy oil is Alberta's largest export so it is the main concern of this analysis. Also heavy oil production is expected to continue growing. We are concerned with the change in mean spread and volatility and the timing of regime changes. The Midwest U.S. is the primary export market for Canadian crude oil (70\%) so we will consider first the WTI-WCS and the WTI-ESS price spreads. The Gulf Coast and the West coast are becoming more important markets for Canadian heavy oil so we will also consider the Mexican Maya-WCS spread. If capacity constraints are affecting Canadian prices we should see the means of the WTIWCS and Mexican Maya-WCS spreads increase and the timing of regime changes should be similar. To ensure our results are reflecting capacity constraints between Alberta and desired export markets we consider in addition the spreads for downstream crude oils: Brent-WTI, WTI-Mexican Maya, and Brent-Mexican Maya. WTI should experience some similar results to WCS as the unconventional crude oil boom (oil sands and shale oil production) resulted in congestion in Cushing. However, if the increased discount WCS receives is the result of constrained capacity, then the Brent-Mexican Maya spread regimes changes should display different timing, i.e. the Brent-Mexican Maya spread is used as a proxy for variations in the quality differential between heavy and light crude oils.

The estimation results for six two regime Markov-switching models with fixed transition

\footnotetext{
${ }^{14}$ The crude-by-rail shipments and inventory held by crude oil transporters data was collected from Statistics Canada Tables 126-0001 and 404-0002. Crude-by-rail shipments was converted from tonnes to thousands of cubic metres using the following ratio 1 tonne $=0.0012 \times 1000 \mathrm{~m}^{3}$.
} 


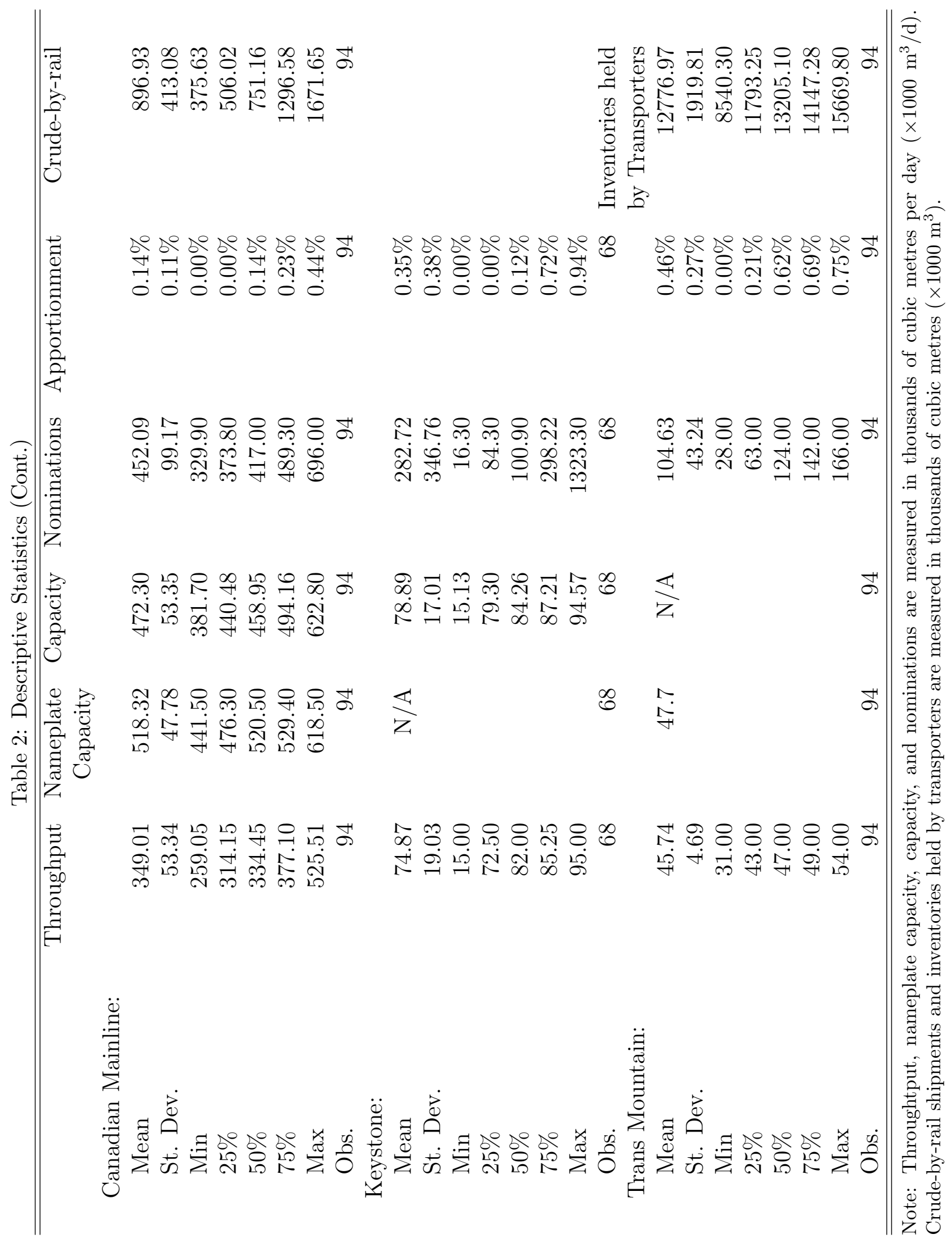


probabilities are presented in Table 3. The spread in each model is simply the price difference between two crude oils. Our analysis will focus on the results of WTI-WCS spread Markovswitching model. The results of the other price spreads models considered will help us infer whether the increased spread between WTI and WCS was the result of binding capacity.

Before discussing the results in Table 3, we test for the presence of two regimes, for all price spreads considered, using the likelihood ratio (LR) test proposed by Garcia (1998). Garcia argues that standard tests are not applicable for testing for two regimes because under the null hypothesis transition probabilities are not identified and the score vector is zero. He derives the asymptotic null distribution of an LR test for two-state Markov-switching models. The test has a null hypothesis of one regime (autoregressive model) versus an alternative of two regimes (Markov-switching model). Garcia's LR statistic is specified as

$$
L R=2 *(\mathcal{L}(\hat{\theta}, \hat{\phi})-\mathcal{L}(\tilde{\theta}))
$$

where $\mathcal{L}(\hat{\theta}, \hat{\phi})$ is the log-likelihood from the unrestricted model (Markov-switching model) with $\phi=\left(p_{11}, p_{22}\right)$ and $\mathcal{L}(\tilde{\theta})$ is the log-likelihood from the restricted model (autoregressive model). An autoregressive model of order one is estimated to calculate the test statistic (the results are presented in Table 6 in the Appendix). Garcia's LR statistic is included in Table 3. For each of the price pairs the null hypothesis is rejected in favour of the Markov-switching model at the $99 \%$ level. $^{15}$

\subsection{WTI-WCS spread}

The maximum likelihood estimates for the WTI-WCS spread two regime Markov-switching model are reported in the first column of Table 3. The regime dependent means, standard deviations, autoregressive coefficients, and transition probabilities are all individually statistically significant. The results indicate there are two distinct regimes for the WTI-WCS spread. One regime is characterized by a low mean and low standard deviation, we refer to this regime as regime 1 . The mean spread in regime 1 of $\$ 15.16$ is roughly consistent with estimated transport costs and the market value of the quality difference and has a relatively small standard deviation of $\$ 1.397$ per week. The other regime, labelled regime 2 , is characterized by a high mean and high standard deviation. The mean spread in regime 2 is $\$ 20.35$, which exceeds estimated transport costs and the market value of the quality difference and the standard deviation is $\$ 3.729$ per week. The coefficient of variation doubles from 0.092 in regime 1 to 0.183 in regime 2 . The results from Table 3 also show that, the autoregressive coefficient varies across regimes. In regime 1, the spread is highly correlated with previous values, $\rho_{1}=0.948$. In regime 2 , the spread is less correlated with past value, $\rho_{2}=0.878$. The estimated parameters in our two regime Markov-switching model support the theoretical predictions and our hypothesis. In one regime there is a smaller mean spread, less variability, and more correlation between periods as spare transportation capacity can be used to smooth supply and demand shocks between Alberta and the Midwest U.S. In the other regime, the mean spread increases, is more variable, and is less correlated between periods as prices in each region are affected by local supply and demand shocks that cannot be smoothed because of capacity constraints.

\footnotetext{
${ }^{15}$ Critical values are from Garcia (1998) (Table 1, p. 773).
} 


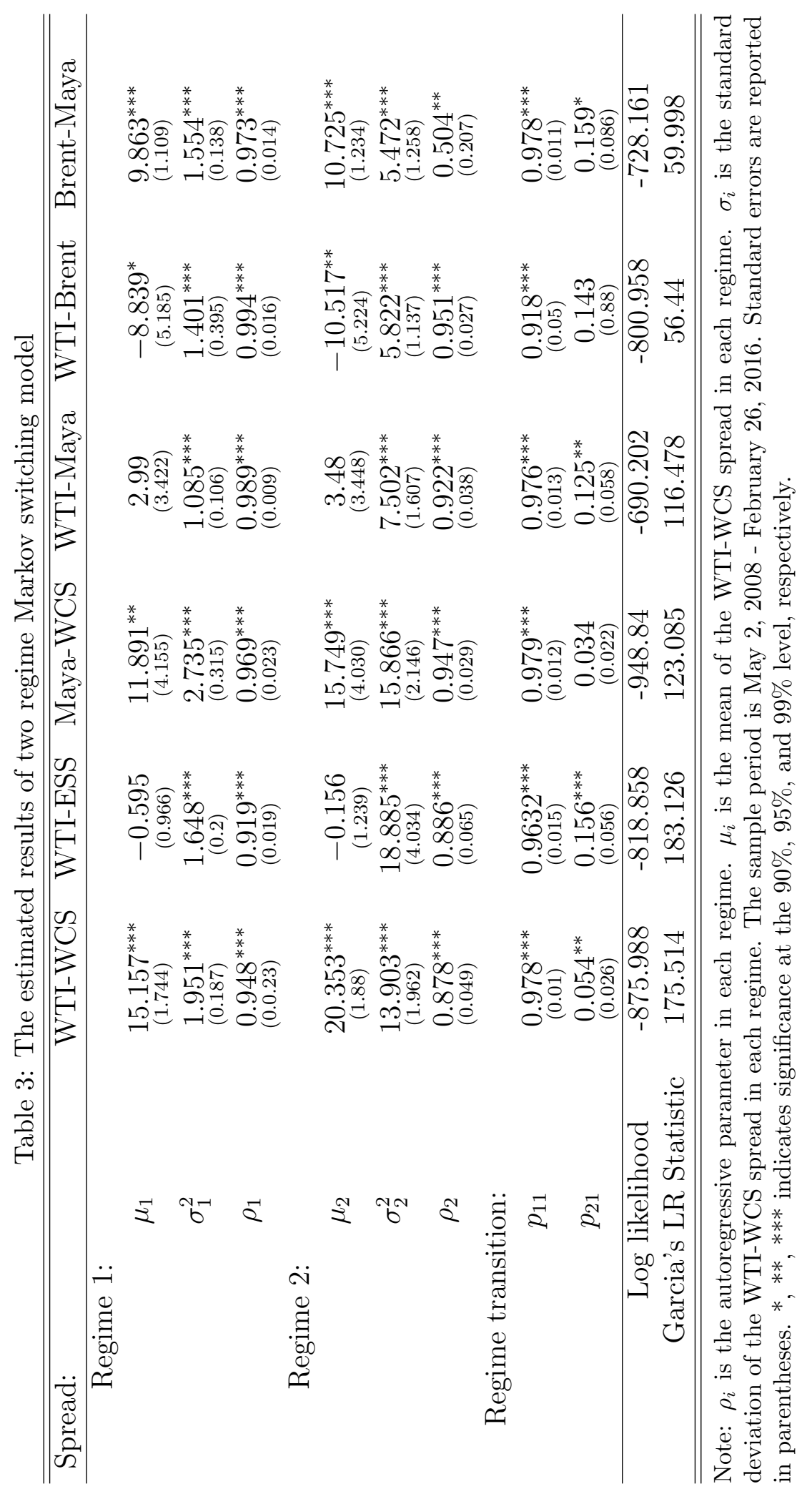


Transition probabilities represent the unconditional probability that the price spread will remain in its current regime or switch to one of the other regimes. The transition probabilities, $p_{11}$ and $p_{21}$, are reported in Table 3 for each price spread model. The transition probability matrix for the WTI-WCS spread is

$$
\left[\begin{array}{ll}
p_{11} & p_{21} \\
p_{12} & p_{22}
\end{array}\right]=\left[\begin{array}{ll}
0.978 & 0.054 \\
0.022 & 0.946
\end{array}\right]
$$

Regime 1 is the most stable regime with a 97.8 percent probability of remaining in regime 1. The probability of remaining in regime 2 is 94.6 percent. The WTI-WCS spread model is characterized by relatively few regime changes as the expected duration of regime 1 is 45 weeks and the expected duration of regime 2 is 19 weeks.

\section{$5.2 \quad$ WTI-ESS Spread}

ESS is a light sweet crude oil, similar in quality to WTI, that is located in Edmonton, Alberta. Light and heavy crude oil compete for space on Canada's pipeline system, if WCS is affected by capacity constraints there should be evidence that ESS is also affected. The estimation results for a two regime Markov-switching model for the WTI-ESS spread are present in Table 3. The standard deviation and correlation coefficient are individually statistically significant. Regime 1 is characterized by a low standard deviation and high autocorrelation and regime 2 has a high standard deviation and low autocorrelation. The standard deviation increases from 1.235 in regime 1 to 4.232 in regime 2 and the autocorrelation coefficient decreases from 0.919 in regime 1 to 0.886 in regime 2. Surprisingly, the mean value of the WTI-ESS spread is not significantly different from zero in both regimes. There is no quality difference between the two crude oils so we would expect the WTI-ESS spread to be smaller than the WTI-WCS spread. However, if transportation capacity is constrained, we would expected a location premium for WTI in regime 2. A possible explanation for this would be if there were sufficient domestic refining capacity the light sweet crude then pipeline capacity could be less important.

\subsection{Mexican Maya-WCS spread}

As a heavy crude oil with access to tidewater, Mexican Maya represents a price that Canadian heavy oil producers could expect to receive once their oil is transported to tidewater as it is of similar quality. Canadian heavy oil accesses tidewater in British Columbia (via the Trans Mountain pipeline) and in the Gulf Coast (via the Canadian Mainline and Keystone pipelines), and since the Gulf Coast is downstream of the Midwest U.S., we expect the Mexican Maya-WCS spread to be governed by two regimes similar to the WTI-WCS spread. The results in Table 3 confirms our expectations. Regime 1 has a lower mean spread and standard deviation, and a higher autocorrelation. Regime 2 has a higher mean spread and standard deviation, and a lower autocorrelation. The results again conform to our expectations. One difference is that the Mexican Maya-WCS mean spread in regime 1, $\$ 11.891$, is lower than WTI-WCS mean spread in regime $1, \$ 15.157$. This is expected as the difference of $\$ 3.266$ is attributable to the quality differential as Mexican Maya is a heavy crude while WTI is light. The regime 1 mean for Mexican Maya is somewhat higher that the 
expected spread in the absence of capacity constraints: transport costs are approximately $\$ 8$ to $\$ 9.55$ per barrel according to the NEB (2014). It is also notable that the difference between regime means for the Mexican Maya-WCS spread is $\$ 3.858$ while the difference between regime means for WTI-WCS spread is $\$ 5.196$, suggesting that the shadow price of capacity is lower for Trans Mountain pipeline than for those flowing into the United States.

\subsection{Downstream spreads}

The three price spreads considered above all contained a crude oil located in Alberta. Now we consider downstream spreads: WTI-Mexican Maya, WTI-Brent, and Brent-Mexican Maya. A similar pattern may emerge for price spreads containing WTI as congestion at Cushing caused inventories to build up in the Midwest U.S. pushing WTI down relative to tidewater crude oils. The WTI-Mexican Maya spread has a low standard deviation regime and a high standard deviation regime. The mean spread in each regime is not significantly different from zero. The WTI-Brent spread has a low mean and standard deviation regime and a high mean and standard deviation regime. Brent has an advantage over WTI in each regime. Congestion at Cushing reduced WTI on average by $\$ 1.678$ relative to Brent.

The Brent-Mexican Maya spread is of particular interest as both have tidewater access and so are not reliant on the pipeline system that Alberta crudes are and there is no reason to think that crude oil tanker capacity is particularly related to pipeline capacity. As such, this spread represents tanker shipping costs plus the quality differential between light and heavy crude oil. If the differences in regime for the WTI-WCS spread are due to variations in the quality differential and not pipeline capacity we should see a similar pattern in the BrentMexican Maya spread. We see in Table 3 that while the two regimes have a similar pattern, one regime with higher mean and variance than the other, the difference in mean spreads in the two regimes is relatively small at about 86 cents. This supports our interpretation that much of the difference in the mean spread for WTI-WCS can be attributed to capacity constraints.

\subsection{Regime probabilities}

The Markov-switching model allows us to compute an estimate of the probability of being in each regime. Figures 2 and 3 show the smoothed probability of being in regime 2 for the six prices spreads considered. Figure 2 has only those price spreads that include a crude oil located in Alberta while Figure 3 presents the other prices spreads. The smoothed probability is the probability of being in a given regime at a given point in time using the full data sample $\left(p\left(s_{t} \mid \psi_{T}\right)\right)$. The smoothed probabilities were computed using Kim's (1994) smoothing algorithm. These probabilities can be used to understand the persistence of each regime and the most probable regime at each time period.

Figure 2 shows the WTI-WCS and Mexican Maya spreads are likely in regime 2 continuously from 2012 to 2014. The WTI-ESS spread switches much more between regime 1 and 2 from 2011 to 2014. All three spreads are likely in regime 1 from early 2009 to mid 2010 and after late 2014. The timing of regime 2 identified by the model seems to correspond to periods of constrained pipeline capacity out of Alberta as mentioned in the Introduction. Figure 3 adds further support to the claim that WCS is affected by capacity 
Figure 2: Smoothed probability of regime two for upstream spreads

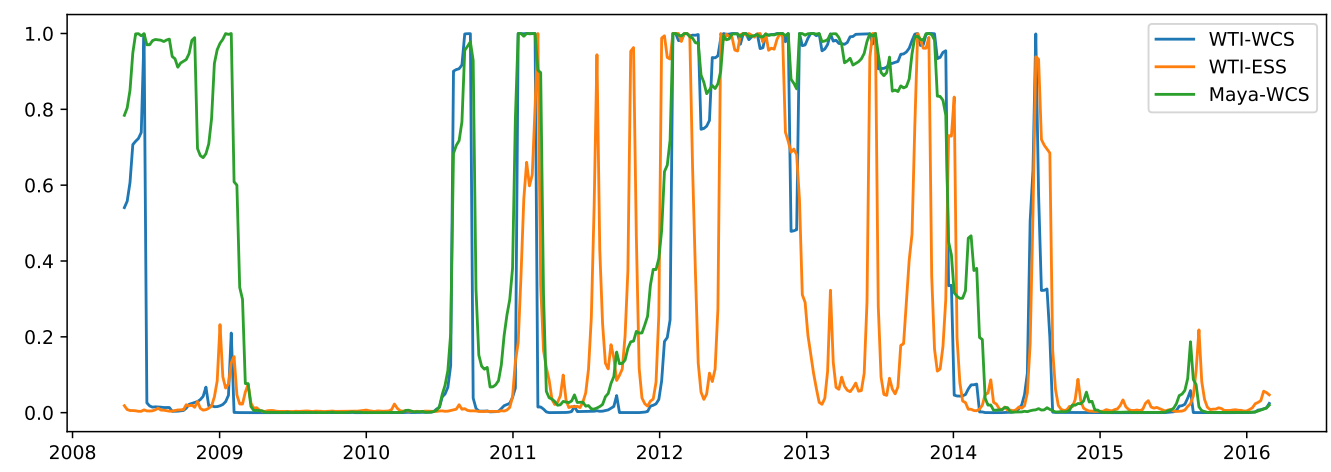

Figure 3: Smoothed probability of regime two for downstream spreads

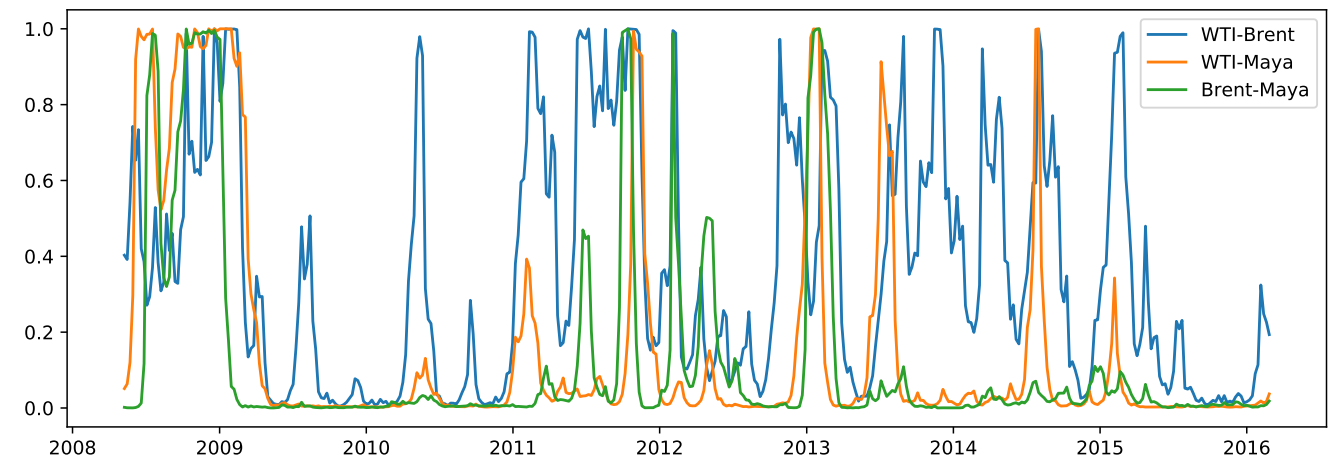


constraints. The WTI-Mexican Maya spread spends short periods of time in regime 2, the expected duration of regime 2 is 8 weeks, and those periods are spread over the full time sample. The Brent-Mexican Maya spread regime 2 smoothed probability is very similar to that of the WTI-Mexican Maya spread, suggesting that factors specific to Mexican Maya are driving the regime changes. The WTI-Brent spread frequently switches between the two regimes. The dramatic difference in predicted regimes between Figure 3 and the spreads involving WCS in Figure 2 are again suggestive that capacity constraints at times affect spreads between WCS and both WTI and Mexican Maya. Also of note is that these regime probabilities suggest pipeline congestion is not ubiquitous: a significant fraction of time is spent in the uncongested regime.

\subsubsection{Alternative specifications of the WTI-WCS spread model}

Along with estimating a two regime Markov-switching model, where all parameters can vary across regimes, we estimate three alternative models for the WTI-WCS spread in order to check the robustness of the results. The first two models allow for a non-switching regressor so that the estimated model becomes

$$
y_{t}-\mu_{s_{t}}=\rho_{s_{t}}\left(y_{t-1}-\mu_{s_{t-1}}\right)+\beta X_{t}+\epsilon_{t},
$$

In one specification, labelled Trend, we include a trend that does not switch across regimes in order to check that our Markov-switching model is not simply picking up a trend. In the second specification, labelled FX, we add the Canadian dollar / U.S. dollar exchange rate. As crude oil production costs are incurred in Canadian dollars and the spread measured in U.S. dollars, the exchange rate may influence the price spread and is also available at the weekly frequency we are working with. In the final specification we shorten the sample period to January 9, 2009 to November 21, 2014 in order to exclude the period of financial crisis and the dramatic decrease in oil prices in 2015. We label this model ATP. The results are presented in Table 4. For all three models the mean spread, standard deviation, and the autocorrelation coefficient are individually statistically significant. The time trend is not statistically significant in the Trend model and the exchange rate is not significant in the FX model. All three models also support the hypothesis that there are two distinct regimes governing the WTI-WCS spread. In each specification the difference between means in each regime is approximately $\$ 5$, consistent with the simple first order autoregressive Markov-switching model presented above.

\section{Time-varying transition probabilities}

To allow for the possibility that the likelihood of binding capacity constraints may have changed over time, we extend the analysis to allow the transition probabilities to vary over time. We do so by allowing the $p_{i j}$ to depend on covariates that plausibly are correlated with binding pipeline capacity. In addition to a simple time trend we examine the quantity of oil shipped by rail and the inventories of crude oil held by transporters. Shipping crude oil by rail is a higher cost alternative (and itself subject to availability of appropriate rail cars) so we would expect higher rail shipments to be associated with tight pipeline capacity. Similarly 
Table 4: Alternative specifications of the WTI-WCS spread fixed transition probability Markov-switching model

\begin{tabular}{cccc}
\hline \hline & Trend & FX & ATP \\
\hline Regime 1: & $13.141^{* * *}$ & $22.211^{* * *}$ & $17.495^{* * *}$ \\
$\mu_{1}$ & $(2.868)$ & $(5.618)$ & $(2.497)$ \\
$\sigma_{1}^{2}$ & $1.947^{* * *}$ & $1.954^{* * *}$ & $1.747^{* * *}$ \\
$\rho_{1}$ & $(0.187)$ & $(0.181)$ & $(0.288)$ \\
& $0.946^{* * *}$ & $0.942^{* * *}$ & $0.964^{* * *}$ \\
Regime $2:$ & $(0.023)$ & $(0.023)$ & $(0.022)$ \\
$\mu_{2}$ & $18.275^{* * *}$ & $27.456^{* * *}$ & $22.231^{* * *}$ \\
$\sigma_{2}^{2}$ & $(3.014)$ & $(5.577)$ & $(2.354)$ \\
& $13.948^{* * *}$ & $13.879^{* * *}$ & $14.074^{* * *}$ \\
$\rho_{2}$ & $(1.978)$ & $(1.951)$ & $(2.104)$ \\
& $0.876^{* * *}$ & $0.872^{* * *}$ & $0.870^{* * *}$ \\
& $(0.049)$ & $(0.048)$ & $(0.48)$ \\
trend & & & \\
& 0.0091 & & \\
Exchange Rate & $(0.012)$ & & \\
& & -6.438 & \\
Regime transition: & & $(4.898)$ & \\
$p_{11}$ & $0.978^{* * *}$ & $0.971^{* * *}$ & $0.964^{* * *}$ \\
& $(0.010)$ & $(0.017)$ & $(0.019)$ \\
$p_{21}$ & $0.027^{* *}$ & $0.054^{* *}$ & $0.0 .061^{* *}$ \\
& $(0.055)$ & $(0.031)$ & $(0.033)$ \\
\hline Log Likelihood & -875.674 & -875.146 & -683.322 \\
AIC & 1769.348 & 1768.293 & 1382.644 \\
BIC & 1805.45 & 1782.578 & 1412.459 \\
\hline \hline
\end{tabular}

Note: Standard errors are reported in parentheses. ${ }^{*}, * *, * * *$ indicates significance at the $90 \%, 95 \%$, and $99 \%$ level, respectively. 
high or increased inventories of crude oil awaiting shipment would also be an indicator of tight pipeline capacity.

In order to maintain the probabilities between zero and one we use the following specification for the transition probabilities into $s_{1}$ :

$$
\operatorname{Pr}\left[s_{t}=1 \mid s_{t-1}=i\right]=p_{i 1, t}=\frac{e^{\alpha_{i}+\beta_{i} x_{t}}}{1+e^{\alpha_{i}+\beta_{i} x_{t}}} \quad i=1,2,
$$

where $x_{t}$ is the covariate of interest and $\left(\alpha_{1}, \alpha_{2}, \beta_{1}, \beta_{2}\right)$ are parameters to be estimated. The probabilities of transition to $s_{2}$ are then $1-p_{i 1, t}$.

Much of the debate around the construction of new pipelines argues that pipeline capacity has become tighter over time. A simple way to incorporate this idea in our model is to allow the transition probabilities to trend over time. In particular, we start with a model in which the transition probabilities depend on a simple linear trend, $x_{t}=t / T$, with $T$ the length of the sample. The estimates are presented in the first column of Table 5. The estimated means and autoregressive parameters are similar to those in the fixed transition probability case, however the estimated standard deviation in regime 2 is substantially higher with the trending transition probabilities. Hence, these parameters remain consistent with regime 2 associated with a capacity constrained regime. The estimate for the time trend in $p_{11}$ is positive, but not statistically significant so there is no statistical evidence that the probability of remaining in the unconstrained state has changed over time. However, that for $p_{21}$ is statistically significant and negative: the probability of switching from regime 2 to 1 is decreasing over time, which implies that the probability of remaining in regime 2 is increasing over time. This may be consistent with the notion that constrained capacity is increasingly a problem over the sample as once in a capacity constrained state it is less likely to exit it. The estimated probability of transitioning out of the capacity constrained state falls from over $5 \%$ to $1.2 \%$ over the sample period.

The second time-varying transition probability model we examine allows for rail shipments ${ }^{16}$ to affect the transition probabilities since variation in rail shipments may indicate whether or not capacity is tight. Rail shipments exhibit a substantial upward trend during this period, one cause of which was a substantial investment in the specialized railcars necessary for the rail transport of crude oil. Consequently, we use detrended rail shipments for $x_{t}$ where a linear time trend has been removed. The results for this model are reported in the column "Rail" of Table 5. The estimates of the parameters in each regime are broadly similar to those from the model with a linear trend. The means and autoregressive parameters are similar to the fixed transition probability model while the standard deviation in regime 2 is substantially higher. The estimated coefficients on rail shipments are negative for both $p_{11}$ and $p_{21}$ but neither are statistically significant. The negative coefficients are consistent with being in regime 2 when rail shipments are above trend.

The third model we consider allows for the possibility that inventories held by shippers may influence the transition probabilities. The estimates in column "Inventory" of Table 5 use detrended inventories for $x_{t}$. The results are similar to those with rail shipments. The regime coefficients are very similar to those in the other time varying transition probability

\footnotetext{
${ }^{16}$ As both rail shipments and transporter inventories are measured at a monthly frequency, we interpolate the series to weekly in order to use them in our estimation routine.
} 
Table 5: Time-varying switching probabilities

\begin{tabular}{|c|c|c|c|}
\hline & Trend & Rail & Inventory \\
\hline \multicolumn{4}{|l|}{ Regime 1: } \\
\hline$\mu_{1}$ & $\begin{array}{l}15.14^{* * *} \\
(1.587)\end{array}$ & $\begin{array}{l}15.52^{* * *} \\
(1.872)\end{array}$ & $\begin{array}{l}15.43^{* * *} \\
(1.764)\end{array}$ \\
\hline$\sigma_{1}$ & $\begin{array}{l}1.822^{* * *} \\
(0.193)\end{array}$ & $\begin{array}{l}1.917^{* * *} \\
(0.196)\end{array}$ & $\begin{array}{l}1.945^{* * *} \\
(0.182)\end{array}$ \\
\hline$\rho_{1}$ & $\begin{array}{l}0.945^{* * *} \\
(0.021)\end{array}$ & $\begin{array}{l}0.952^{* * *} \\
(0.023)\end{array}$ & $\begin{array}{l}0.950^{* * *} \\
(0.023)\end{array}$ \\
\hline \multicolumn{4}{|l|}{ Regime 2: } \\
\hline$\mu_{2}$ & $\begin{array}{l}19.86^{* * *} \\
(1.697)\end{array}$ & $\begin{array}{l}20.63^{* * *} \\
(1.948)\end{array}$ & $\begin{array}{l}20.71^{* * *} \\
(1.907)\end{array}$ \\
\hline$\sigma_{2}$ & ${ }_{(1.942)}^{14.252^{* * *}}$ & $\begin{array}{l}13.78^{* * *} \\
(1.966)\end{array}$ & $\begin{array}{c}13.675^{* * *} \\
(1.879)\end{array}$ \\
\hline$\rho_{2}$ & $\begin{array}{l}0.885^{* * *} \\
(0.047)\end{array}$ & $\begin{array}{l}0.875^{* * *} \\
(0.049)\end{array}$ & $\begin{array}{l}0.873^{* * *} \\
(0.049)\end{array}$ \\
\hline \multicolumn{4}{|l|}{ Regime transition: } \\
\hline $\begin{array}{l}p_{11}: \\
\text { Constant }\end{array}$ & $\begin{array}{l}2.887^{* * *} \\
(0.639)\end{array}$ & $\begin{array}{l}3.681^{\text {*** }} \\
(0.496)\end{array}$ & $\begin{array}{l}3.983^{* * *} \\
(0.529)\end{array}$ \\
\hline Time & $\begin{array}{l}1.512 \\
(1.386)\end{array}$ & & \\
\hline Rail shipments & & $\begin{array}{c}-1.023 \\
(2.604)\end{array}$ & \\
\hline Inventories & & & $\begin{array}{c}-8.996 \\
(7.086)\end{array}$ \\
\hline \multicolumn{4}{|l|}{$p_{21}:$} \\
\hline Constant & $\begin{array}{l}0.743 \\
(1.180)\end{array}$ & $\begin{array}{l}-2.772^{* * *} \\
(0.560)\end{array}$ & $\begin{array}{c}-3.151^{* * *} \\
(0.568)\end{array}$ \\
\hline Time & $\begin{array}{c}-6.786^{* * *} \\
(2.153)\end{array}$ & & \\
\hline Rail shipments & & $\begin{array}{c}-0.207 \\
(2.589)\end{array}$ & \\
\hline Inventories & & & $\begin{array}{l}12.059 \\
(10.812) \\
\end{array}$ \\
\hline Log likelihood & -865.1 & -867.6 & -866.7 \\
\hline $\mathrm{AIC}$ & 1750.2 & 1755.2 & 1753.5 \\
\hline $\mathrm{BIC}$ & 1790.2 & 1795.3 & 1793.5 \\
\hline
\end{tabular}

Note: $\rho_{i}$ is the autoregressive parameter in each regime. $\mu_{i}$ is the mean of the WTI-WCS spread in each regime. $\sigma_{i}$ is the standard deviation of the WTI-WCS spread in each regime. The sample period is May 2, 2008 - February 26, 2016. Standard errors are reported in parentheses. ${ }^{*},{ }^{* *},{ }^{* * *}$ indicates significance at the $90 \%, 95 \%$, and $99 \%$ level, respectively. 
Figure 4: Smoothed probability of regime two

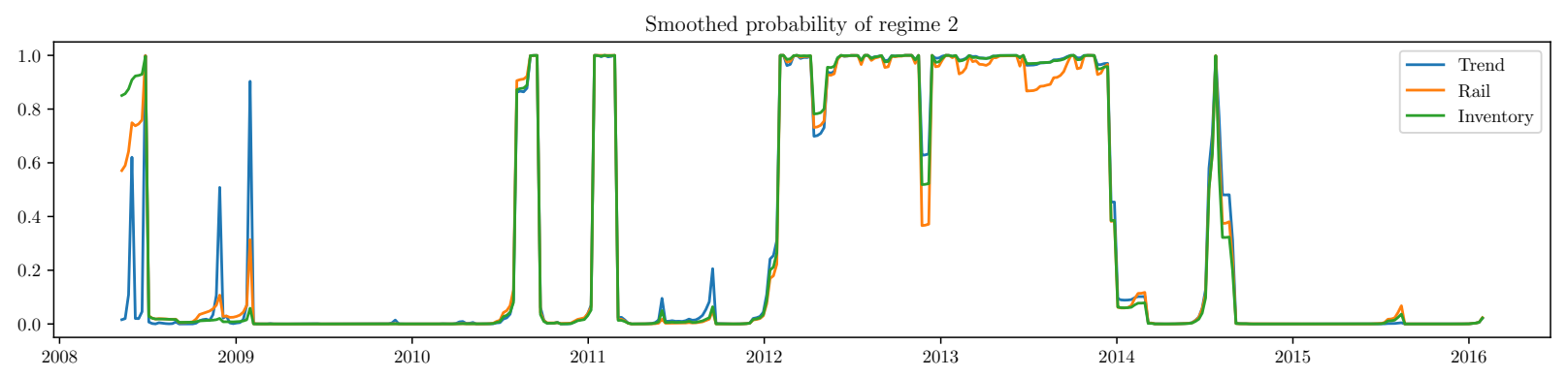

models and the inventory coefficients in the transition probabilities are not statistically significant.

While these three models of time-varying transitions probabilities differ substantially on their estimation of the transition probabilities, they are largely in agreement on assigning time periods to regimes. We plot the smoothed probabilities of being in regime two in Figure 4, which shows substantial uniformity in these predictions across the three models. In addition, their predictions in this respect also largely conform to that of the fixed transition probability model for the WTI-WCS spread in Figure 2, suggesting that not much is added to the identification of regimes by the time-varying transition probability models.

\section{Comparison with pipeline capacity utilization data}

Monthly data on pipeline throughput and capacity has recently been released by Canada's National Energy Board, ${ }^{17}$ allowing a comparison with the predictions of the model above. In particular we examine the extent to which the predicted regimes for the WTI-WCS spread are consistent with the available data on pipeline capacity. As we do not have weekly capacity information available, we simply provide a graphical analysis to compare with the model predictions.

There are two measures of capacity utilization reported for these pipelines, one based on throughput relative to capacity (capacity utilization), and another based on the rationing of shipments when there is excess demand for pipeline services (apportionment). Of the three pipelines used to transport crude oil out of Alberta (Canadian Mainline, Keystone ${ }^{18}$ and Trans Mountain)apportionment is reported for each while throughput and capacity are not available for Trans Mountain. Consequently, we focus first on the apportionment data and then examine capacity utilization for the Keystone pipeline which provides the most direct connection between Hardisty, Alberta and Cushing, Oklahoma.

Apportionment is associated with regulations regarding the rationing of excess demand for pipeline services. When demand exceeds available capacity shippers are apportioned capacity proportional to their nominated shipments. For each month, the percentage by which each shippers requested shipments are reduced is recorded as the apportionment percent which represents a measure of how tight pipeline capacity was during that month. Figure 5

\footnotetext{
${ }^{17}$ http://www.neb-one.gc.ca/nrg/ntgrtd/pplnprtl/pplnprfls/index-eng.html

${ }^{18}$ The Keystone pipeline only began operation in 2011, part way through our sample
} 
plots these apportionment percentages for the two pipelines that take crude oil into the United States: Keystone and Canadian Mainline. For comparison with the model predictions, Figure 5 has shaded bands to indicate when the fixed-transition Markov-Switching model of the WTI-WCS spread predicts that regime two is most likely (the smoothed probability of regime two is larger than 0.5). For the 2012 to late 2013 period in which the price data is consistent with constrained capacity, apportionment on the Keystone pipeline is also consistently high. Indeed, Keystone apportionment appears to be the one most in accord with the estimated regimes, mainly differing by suggesting that capacity was rationed substantially well into 2014 which the estimates suggest was largely not capacity constrained. Conversely, apportionment on the Canadian Mainline pipeline is not as strongly correlated

with the estimated regimes. Canadian Mainline apportionment is relatively low and its highest values occur after the start of 2014 .

The Trans Mountain pipeline transports crude oil to tidewater at the port of Vancouver, British Columbia, so the Maya heavy crude oil benchmark is the more appropriate one as that is also a tidewater benchmark. Figure 6 plots apportionment for the Trans Mountain pipeline along with the predicted periods of tight capacity as determined from the Maya-WCS model of Table 3. Transmountain apportionment is relatively high during the 2012 to late 2013 period, but it starts earlier and ends later than the model prediction. The probability of Regime 2 for the Maya-WCS spread is broadly similar to that for WTI-WCS, so as in the case for the U.S.-bound pipelines, the estimated periods of tight pipeline capacity are not entirely consistent with the Transmountain apportionment data. The periods of tight capacity as estimated from the price data are fewer than what is suggested by the apportionment data.

While pipeline throughput and capacity data is not consistently available for all three pipelines, we do have it for the Keystone pipeline. Combining throughput of both light and heavy crude oil for the Keystone pipeline relative to reported capacity gives us a measure of capacity utilization. We plot this in Figure 7, where we see that there are months in the 2012 to late 2013 period during which Keystone is operating at less than 100\% capacity even though the estimates from the price data suggest a capacity constrained regime is in operation. In addition, this data also suggests that Keystone is frequently at capacity following 2014 while the estimates from the price data suggest Regime 1 is occurring.

\section{Conclusion}

This article considers the impact that constrained pipeline capacity may have on the distribution of the spread between crude oil prices in Alberta and relevant benchmark world prices in light of the theory of spatial pricing with a capacity constrained transportation technology. There has been a significant push to expand Canada's crude oil pipeline system as a result of the larger than normal spread between WTI and WCS that existed from 2011 to the end of 2014. We modelled price spreads using a two regime Markov-switching model where one regime corresponds to times when there is sufficient transportation capacity and the other regime corresponds to times when there is insufficient transportation capacity. Our results are consistent with predictions in the spatial arbitrage literature: when there is sufficient transportation capacity the WTI-WCS spread reflects transport costs and quality differences, and the spread is less volatile, while during periods of tight capacity, the WTI- 
Figure 5: Pipeline apportionment to the U.S.

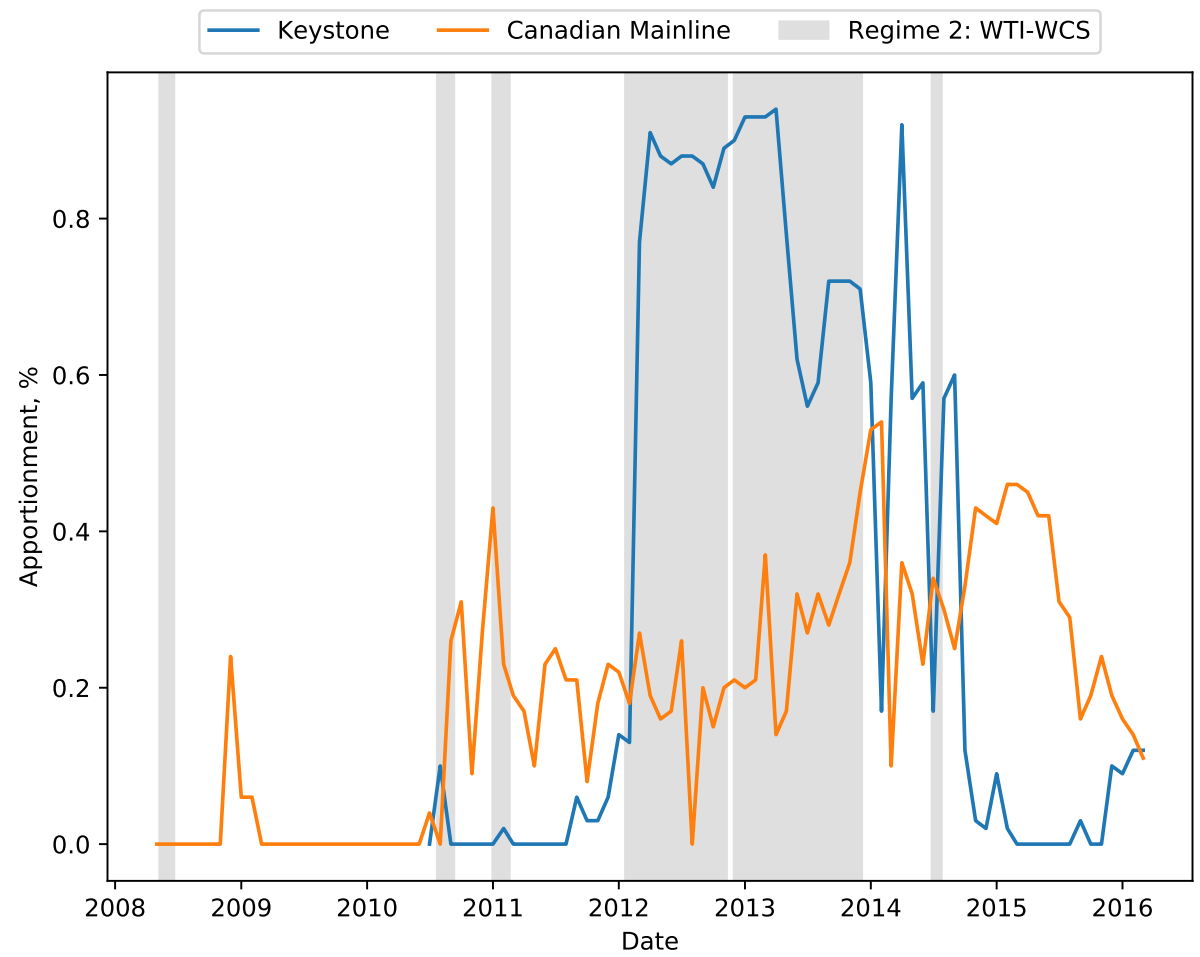

Figure 6: Trans Mountain pipeline apportionment

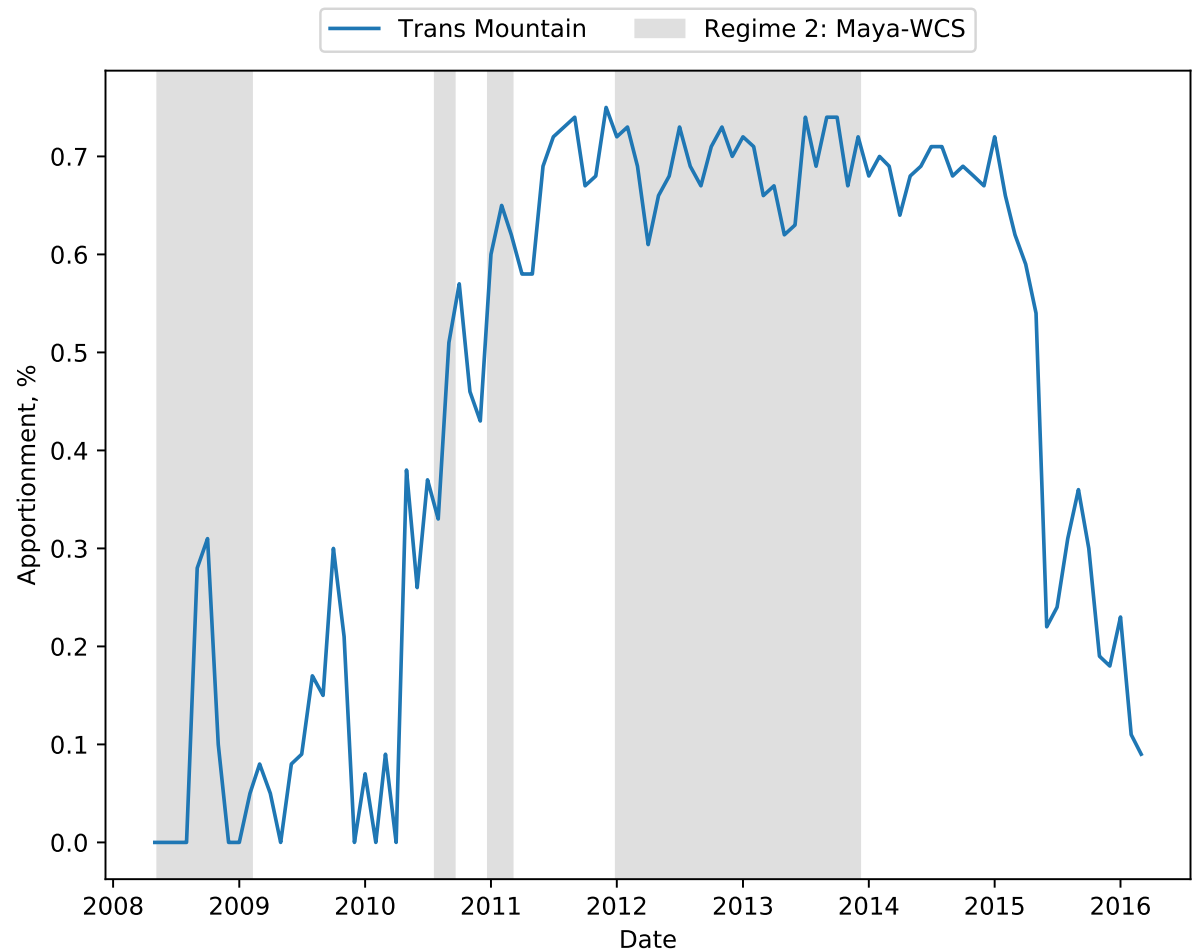


Figure 7: Keystone capacity utilization

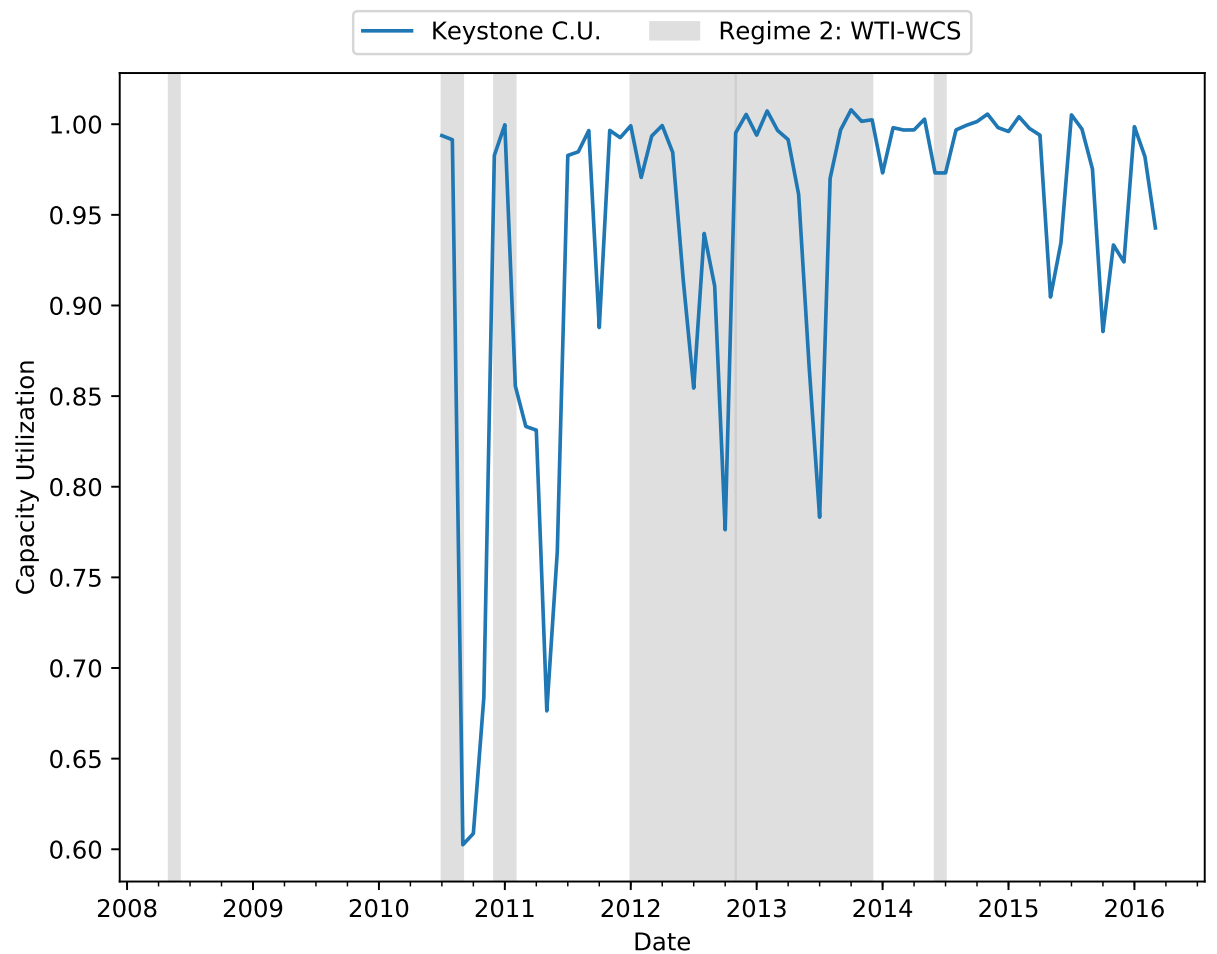

WCS spread exceeds transport costs and quality difference and the spread is more volatile as supply cannot be moved between regions to smooth supply and demand imbalances. We find similar results for the spread between WCS and Mexican Maya, which provides additional evidence that the regimes represent pipeline congestion instead of variations in the quality premium.

We extended the analysis to allow for non-switching regressors and for transition probabilities to be time-varying. These extension had little effect on the identification of the timing of regimes: the assignment of periods to regimes was similar across all models examined. Finally, we compared the Markov-switching results to recently released data on pipeline capacity. There are some inconsistencies between the two measures. In particular, our estimates based on price data suggest a zero shadow price of capacity at the end of the sample, while measured capacity utilization indicates the opposite.

\section{References}

Avalos, R., Fitzgerald, T. and Rucker, R. R.: 2016, Measuring the effects of natural gas pipeline constraints on regional pricing and market integration, Energy Economics 60, 217 $-231$.

URL: http://www.sciencedirect.com/science/article/pii/S0140988316302614

Coleman, A.: 2009, A model of spatial arbitrage with transport capacity constraints and 
endogenous transport prices, American Journal of Agricultural Economics 91(1), 42-56.

Cremer, H., Gasmi, F. and Laffont, J.-J.: 2003, Access to pipelines in competitive gas markets, Journal of Regulatory Economics 24(1), 5-33.

URL: https://doi.org/10.1023/A:1023943613605

Cremer, H. and Laffont, J.-J.: 2002, Competition in gas markets, European Economic Review 46(4), $928-935$.

URL: http://www.sciencedirect.com/science/article/pii/S0014292101002264

Engel, C. and Hamilton, J. D.: 1990, Long swings in the dollar: Are they in the data and do markets know it?, The American Economic Review 80(4), 689-713.

Fattouh, B.: 2010, The dynamics of crude oil price differentials, Energy Economics 32(2), 334 -342 .

URL: http://www.sciencedirect.com/science/article/pii/S0140988309000978

Galay, G.: 2018, The impact of spatial price differences on oil sands investments, Energy Economics 69, 170-184.

Garcia, R.: 1998, Asymptotic null distribution of the likelihood ratio test in Markov switiching models, International Economic Review 39(3), 763-788.

Garcia, R. and Perron, P.: 1996, An analysis of the real interest rate under regime shifts, The Review of Economics and Statistics 78(1), 111-125.

Goldfeld, S. M. and Quandt, R. E.: 1973, A Markov model for switching regressions, Journal of Econometrics 1, 3-16.

Hamilton, J. D.: 1989, A new approach to the economic analysis of nonstationary time series and the business cycle, Econometrica 57(2), 357-384.

Hamilton, J. D.: 1994, Time Series Analysis, Princton University Press.

Hammoudeh, S. M., Ewing, B. T. and Thompson, M. A.: 2008, Threshold cointegration analysis of crude oil benchmarks, The Energy Journal 29(4), 79-95.

Kim, C. J.: 1994, Dynamic linear models with Markov-switching, Journal of Econometrics 60, $1-22$.

Kim, C. J. and Nelson, C. R.: 1999, State-Space Models with Regime Switching, The MIT Press.

Kim, C. J., Nelson, C. R. and Startz, R.: 1998, Testing for mean reversion in heteroskedastic data based on Gibbs-sampling-augmented randomization, Journal of Empirical Finance 5, 131-154.

Kuck, K. and Schweikert, K.: 2017, A Markov regime-switching model of crude oil market integration, Journal of Commodity Markets 6, 16 - 31 .

URL: http://www.sciencedirect.com/science/article/pii/S2405851316301155 
Mann, J. and Sephton, P.: 2016, Global relationships across crude oil benchmarks, Journal of Commodity Markets 2(1), 1 - 5.

URL: http://www.sciencedirect.com/science/article/pii/S2405851315300179

McKeown, L., Bristow, C. and Cauette, A.: 2016, Canada's shifting sands: Oil production, distribution, and implications, 2005 to 2014, Technical report, Statistics Canada.

National Energy Board: 2014, Canadian pipeline transportation system energy market assessment, Technical report, National Energy Board.

Oliver, M. E., Mason, C. F. and Finnoff, D.: 2014, Pipeline congestion and basis differentials, Journal of Regulatory Economics 46(3), 261-291.

URL: https://doi.org/10.1007/s11149-014-9256-9

Reboredo, J. C.: 2011, How do crude oil prices co-move?: A copula approach, Energy Economics 33(5), 948 - 955.

URL: http://www.sciencedirect.com/science/article/pii/S0140988311000892

Samuelson, P. A.: 1952, Spatial price equilibrium and linear programming, The American Economic Review 42(3), 283-303.

Samuelson, P. A.: 1971, Stochastic speculative price, Proceedings of the National Academy of Sciences of the United States of America 68(2), 335-337.

Takayama, T. and Judge, G. G.: 1971, Spatial and Temporal Price and Allocation Models, North-Holland.

Zhang, Y. J. and Zhang, L.: 2015, Interpreting the crude oil price movements: Evidence from the Markov regime switching model, Applied Energy 143, 96-109. 


\section{Appendices}

Table 6: Autoregressive model estimates

\begin{tabular}{ccccccc}
\hline \hline Spread: & WTI-WCS & WTI-ESS & Maya-WCS & WTI-Maya & WTI-Brent & Brent-Maya \\
\hline$\mu$ & $17.354^{* * *}$ & -0.734 & $12.703^{* * *}$ & 6.048 & $-5.83^{*}$ & $10.839^{* * *}$ \\
& $(1.676)$ & $(1.133)$ & $(3.262)$ & $(4.024)$ & $(3.159)$ & $(1.364)$ \\
$\rho$ & $0.927^{* * *}$ & $0.905^{* * *}$ & $0.959^{* * *}$ & $0.983^{* * *}$ & $0.973^{* * *}$ & $0.946^{* * *}$ \\
$\sigma^{2}$ & $(0.018)$ & $(0.021)$ & $(0.014)$ & $(0.009)$ & $(0.011)$ & $(0.016)$ \\
Log likelihood & 2.547 & 2.237 & 2.853 & 1.502 & 1.831 & 1.54 \\
AIC & -963.745 & -910.421 & -1010.385 & -748.441 & -829.18 & -758.16 \\
BIC & 1933.489 & 1826.843 & 2026.77 & 1502.882 & 1664.36 & 1522.32 \\
\hline \hline
\end{tabular}

Note: $\rho_{i}$ is the autoregressive parameter in each regime. $\mu_{i}$ is the mean of the WTI-WCS spread in each regime. $\sigma_{i}$ is the standard deviation of the WTI-WCS spread in each regime. The sample period is May 2, 2008 - February 26, 2016. Standard errors are reported in parentheses. *, **,*** indicates significance at the $90 \%, 95 \%$, and $99 \%$ level, respectively. 